\title{
Immunopositivity for Siglec-15 in gastric cancer and its association with clinical and pathological parameters
}

\author{
Michael Williams Leal Quirino, ${ }^{1 *}$ Michelly Cristiny Pereira, ${ }^{1 *}$ Maria de Fátima Deodato de Souza, ${ }^{1}$ \\ Ivan da Rocha Pitta, ${ }^{1}$ Antônio Felix da Silva Filho, ${ }^{1}$ Mário S. de Souza Albuquerque, ${ }^{1}$ \\ Amanda Pinheiro de Barros Albuquerque, ${ }^{1}$ Mário Rino Martins, ${ }^{2}$ Maira Galdino da Rocha Pitta, ${ }^{1}$ \\ Moacyr Jesus Barreto de Melo Rêgo ${ }^{1}$
}

${ }^{1}$ Laboratório de Imunomodulação e Novas Abordagens Terapêuticas - LINAT / Núcleo de Pesquisa em Inovação Terapêutica Suely Galdino - NUPIT SG, Universidade Federal de Pernambuco, Recife

${ }^{2}$ Hospital do Câncer de Pernambuco - HCP, Recife PE, Brazil

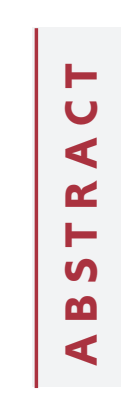

\begin{abstract}
The sialic acid-binding immunoglobulin-type lectin Siglec-15 is a promising target for cancer immunotherapy in several tumor types. The present study aimed to investigate Siglec-15 expression in gastric cancer (GC) patient tissues and to evaluate its clinical value. Siglec-15 expression was evaluated by immunohistochemistry in 71 patients. Siglec-15 staining was observed in tumor cells of 53 (74.64\%) patients, with significant association with histologic classification and angiolymphatic invasion $(\mathrm{p}<0.05)$. Immunohistochemistry analysis also detected Siglec-15 in tumor-associated stroma cells (macrophages/myeloid cells). There was no significant association with outcome parameters. Siglec-15 expression in well differentiated histological GC tissues and in the tumor microenvironment are potential targets to be further investigated as a novel prognostic factor for GC.
\end{abstract}

Key words: Siglec; sialic acid; immunohistochemistry; clinical-pathological analyses.

Correspondence: Moacyr Jesus Barreto de Melo Rêgo, Laboratório de Imunomodulação e Novas Abordagens Terapêuticas (LINAT), Núcleo de Pesquisa em Inovação Terapêutica Suely Galdino (NUPIT-SG), Universidade Federal de Pernambuco, Av. Prof. Moraes Rego 1235, Cidade Universitária, Recife, PE 50670-901, Brazil. E-mail: moacyr.rego@gmail.com

Contributions: All the authors made a substantive intellectual contribution. All the authors have read and approved the final version of the manuscript and agreed to be accountable for all aspects of the work.

Conflict of interest: The authors declare that they have no competing interests, and all authors confirm accuracy.

Funding: The authors thank CNPq, CAPES and FACEPE for financial support.

Availability of data and materials: The data used to support the findings of this study are available from the corresponding author on reasonable request.

Ethical Approval: Ethical approval was obtained from the Human Ethics Committee of the Hospital do Câncer de Pernambuco (HCP) (CAAE: 39976214.90000 .5205$).$ 


\section{Introduction}

Gastric adenocarcinoma (GC) is the fifth most common cancer globally. ${ }^{1,2}$ Although there are well-established risk factors, the diagnosis of GC is often late, with a poor prognosis and advanced cases. There is an urgent need for new diagnostic and prognostic biomarkers for $\mathrm{GC}^{3}{ }^{3}$ Glycosylation is an important post-translational modification for proteins and is associated with crucial roles in cells, such as differentiation, transformation, cell growth and immune surveillance and has been reported in several human diseases including cancer. ${ }^{4,5}$ Changes in the glycosylation profile in cancer mainly result from changes in the size of the glycan, generally towards shorter O-glycans and more branched N-glycans. In addition they impact on the nature of terminal epitopes in glycan chains mediated by changes in the process of sialylation and fucosylation, and changes in the expression of glycosfingolipids. ${ }^{6,7}$ Thus, the alterations in glycosylation have been recognized as a hallmark of cancer, with implications in carcinogenesis, angiogenesis, and metastasis. ${ }^{8}{ }^{89}$ Many tumor biomarkers used in the practical clinic are sialylated glycoproteins. ${ }^{5}$

Sialic acid plays an important role due to its size, hydrophilic characteristic and electronegative charge; ${ }^{10}$ Siglecs, endogenous lectins that bind to glycans and regulate signal transduction, are expressed and have immunosuppressive properties on immune cells. ${ }^{8}$ Siglec-15 is an immunoglobulin-like lectin that acts as a sialic acid binder and it can be overexpressed in many human cancers, including colon, kidney, liver, thyroid cancer. ${ }^{11,12}$ A recent study showed that Siglec-15 suppresses $\mathrm{T}$ cell responses and may contribute to dysfunctional immunity in the tumor microenvironment, by functional regulation of macrophages, with high potential to become a target for immunotherapy. ${ }^{5}$ The present study evaluated Siglec-15 in GC tissues and adjacent noncancerous tissues and investigated the association of this protein with clinicopathological parameters.

\section{Materials and Methods}

\section{Patients and samples}

We selected formalin-fixed, paraffin-embedded tissue samples from patients diagnosed with GC, histopathologically reexamined by pathologist who underwent surgical resection at the Pernambuco Cancer Hospital, between 2013 and 2016. The following variables were collected in medical charts: age, sex, tumor type, location, pathological staging, Lauren classification, treatment type, lymph node number and location, positive lymph nodes, recurrence, metastasis, and death. The present study included 71 patients, 24 female patients $(33.80 \%)$ and 47 males $(66.19 \%)$ with a mean age of $59.25 \pm 13.30$ (range $30-89$ ). According to the histological grade, 20 cases $(28.16 \%)$ were classified as well differentiated (G1), $15(21.12 \%)$ as moderately differentiated (G2), and $36(50.70 \%)$ as poorly differentiated (G3). Regarding the surgical staging, most patients were at stage T3 (51 cases; 71.83\%), 6 cases $(8.45 \%)$ were at stage T1, $12(16.90 \%)$ as T2, and only 2 $(2.81 \%)$ at T4. All the clinicopathological characteristics of GC patients are presented in Table 1 .

\section{Immunohistochemistry}

Tissue sections of $4 \mu \mathrm{m}$ taken from tissue array blocks underwent deparaffinization with xylol, alcohol rehydration and antigenretrieval using citrate buffer at $96^{\circ} \mathrm{C}$ for $15 \mathrm{~min}$. After cooling to room temperature, the slides were blocked against endogenous peroxidase activity with $0.3 \% \mathrm{H}_{2} \mathrm{O}_{2}$ and $1 \%$ methanol solution.
Following, the blockade of the non-specific bonds was made with bovine serum albumin 1\% in Phosphate Buffer Saline (PBS). The sections were then incubated with rabbit polyclonal antibody against human Siglec-15, (Cusabio Technology, LLC, Wuhan, China, dilution $1: 100$ ) diluted in PBS/BSA $1 \%$ at $4^{\circ} \mathrm{C}$ overnight. Next, sections were incubated with the amplification system (Easylink On, ImmPRESS ${ }^{\mathrm{TM}}$, and Dako EnVision ${ }^{\mathrm{TM}}$ ) at room temperature for $1 \mathrm{~h}$ was applied and the reaction was visualized with diaminobenzidine (DAB, Sigma-Aldrich). The positive control used was colon and prostate cancer tissue according to the antibody manufacturer's designation (Cusabio Technology, LLC) and negative controls were produced by omitting the primary antibodies (Supplementary Figure 1).

\section{Image analysis}

Histomorphological analysis were performed with an integrated image system (BIOPTICA B20) microscope coupled to a CMOS camera (2584 x 1936 pixels resolution) with ISCapture image capture software. The enzyme labeling site (cytoplasmic, membrane, and perinuclear and nuclear) were also analyzed. Combinations of associated clinical-pathological parameters and outcome parameters were made with enzyme labeling and labeling site. Semi-quantitative analysis of the stained cells was done using immunoreactive score (IRS) classification by analyzing 5 random fields in each slide. ${ }^{13,14}$ IRS $=$ SI (staining intensity) $x$ PP (percentage of positive cells). Staining intensity was determined as 0 is negative; 1 , weak; 2 , moderate; and 3 , strong. The percentage of positive cells was defined as 0 is negative; $1,10 \%$ positive cells; 2 , $11-50 \%$ positive cells; $3,51-80 \%$ positive cells; and 4 , more than $80 \%$ positive cells. The score evaluation was done by two independent evaluators through the analysis of images at 200x magnification.

\section{Outcome analysis}

Survival analyses were made accessing the differential expression for Siglec-15 available in the cBioPortal for Cancer Genomics (http://cbioportal.org). Differences in overall survival and relapse free time were evaluated through three cohorts. ${ }^{15,16}$ Overall survival was defined from the day of the sample intake to the patient's death. Data of the patients who had survived until the end of the observation period were censored at their last follow-up visit.

\section{Statistical analysis}

Fisher's exact test was performed in GraphPad Prism version 7.0. A p-value of $<0.05$ was considered statistically significant. Analysis of outcome was evaluated through Kaplan-Meyer curves with a long-rank test. Multivariate logistic regression analysis was performed using STATA, with stepwise forward selection.

\section{Results}

\section{Siglec-15 expression in gastric cancer}

Siglec-15 was positively labeled in 53 patients (74.64\%), 17 female patients $(23.94 \%)$ and $36(50.70 \%)$ males (Table 1$)$. In neoplastic lesions, Siglec-15 was observed in the cytoplasm in 14 samples $(26.41 \%)$, perinuclear in $4(7.54 \%)$ and nuclear in 1 only sample $(1.88 \%)$. On the other hand, combinations of cytoplasmic, nuclear and perinuclear staining were observed in 34 samples (61.9\%) (Figure $1 \mathrm{~A}, \mathrm{~B})$. Immunohistochemical analysis detected Siglec-15 not only in gastric cancer cells but in tumor-infiltrating macrophages (Figure 1A). In 40 samples (59.70\%) of the 71 patients analyzed presented an adjacent normal tissue, in which 17 $(42.5 \%)$ were SIGLEC-15 positive, especially in the ducts and in 
production cells of the gastric glands. Additionally, Siglec-15 was detected in $40.9 \%(9 / 22)$ of the preneoplastic lesion intestinal metaplasia (IM) (Figure 1C) and it was found significant association between Siglec-15 expression in GC compared to normal nontransformed and IM adjacent gastric tissue (Table 2). Regarding the Siglec-15 and its association with clinical-pathological parameters, its expression was significantly associated histologic classification $(p=0.0022)$ and angiolymphatic invasion $(p=0.041)$. Interestingly, Siglec-15 cellular location staining was also associated to the tumor-node-metastasis (TNM) stage $(\mathrm{p}=0.01)$. Patients

Table 1. Association analysis of Siglec-15 expression with clinicopathological features of gastric cancer patients.

\begin{tabular}{|c|c|c|c|}
\hline Clinicopathological features & $\begin{array}{c}\text { Siglec-15 (+) } \\
\text { n (\%) }\end{array}$ & $\begin{array}{c}\text { Siglec-153 (-) } \\
\text { n (\%) }\end{array}$ & p \\
\hline $\begin{array}{l}\text { Age (years) } \\
\quad \geq 60 \\
\quad<60\end{array}$ & $\begin{array}{l}30(42.25 \%) \\
23(32.39 \%)\end{array}$ & $\begin{array}{c}6(8.45 \%) \\
12(16.90 \%)\end{array}$ & 0.1073 \\
\hline $\begin{array}{ll}\text { Sex } & \\
& \text { Female } \\
& \text { Male } \\
\end{array}$ & $\begin{array}{l}17(23.94 \%) \\
36(50.70 \%)\end{array}$ & $\begin{array}{c}7(9.86 \%) \\
11(15.49 \%)\end{array}$ & $>0.9999$ \\
\hline $\begin{array}{l}\text { Surgery } \\
\text { Total gastrectomy } \\
\text { Partial gastrectomy }\end{array}$ & $\begin{array}{l}24(33.80 \%) \\
29(40.85 \%)\end{array}$ & $\begin{array}{c}8(11.27 \%) \\
10(14.08 \%)\end{array}$ & $>0.9999$ \\
\hline $\begin{array}{l}\text { Neoadjuvant treatment } \\
\text { I } \\
\text { III } \\
\end{array}$ & $\begin{array}{c}49(69.01 \%) \\
4(5.63 \%)\end{array}$ & $\begin{array}{c}17(23.94 \%) \\
1(1.41 \%)\end{array}$ & $>0.9999$ \\
\hline $\begin{array}{l}\text { Surgical staging (TNM) } \\
\text { I - II } \\
\text { III - IV }\end{array}$ & $\begin{array}{l}10(14.08 \%) \\
43(60.56 \%)\end{array}$ & $\begin{array}{c}8(11.27 \%) \\
10(14.08 \%)\end{array}$ & 0.0566 \\
\hline $\begin{array}{l}\text { Surgical staging (TNM) } \\
\text { II } \\
\text { III }\end{array}$ & $\begin{array}{l}5(7.94 \%) \\
42(66.67 \%)\end{array}$ & $\begin{array}{l}7(11.11 \%) \\
9(14.29 \%)\end{array}$ & 0.0075 \\
\hline $\begin{array}{l}\text { Lymph node involvement } \\
\text { Yes } \\
\text { No }\end{array}$ & $\begin{array}{l}36(50.70 \%) \\
17(23.94 \%)\end{array}$ & $\begin{array}{l}10(14.08 \%) \\
8(11.27 \%)\end{array}$ & 0.3979 \\
\hline $\begin{array}{l}\text { Histological grade } \\
\text { GI + GII } \\
\text { GIII } \\
\end{array}$ & $\begin{array}{l}32(45.07 \%) \\
21(29.58 \%)\end{array}$ & $\begin{array}{c}3(4.23 \%) \\
15(21.13 \%)\end{array}$ & 0.0022 \\
\hline $\begin{array}{l}\text { Chemotherapy } \\
\text { Yes } \\
\text { No }\end{array}$ & $\begin{array}{l}28(39.44 \%) \\
25(35.21 \%)\end{array}$ & $\begin{array}{l}10(14.93 \%) \\
8(11.27 \%)\end{array}$ & $>0.9999$ \\
\hline $\begin{array}{c}\text { Radiotherapy } \\
\text { Yes } \\
\text { No } \\
\end{array}$ & $\begin{array}{l}15(21.13 \%) \\
38(53.52 \%)\end{array}$ & $\begin{array}{c}6(8.45 \%) \\
12(16.90 \%)\end{array}$ & 0.7676 \\
\hline $\begin{array}{l}\text { Recurrence } \\
\text { Yes } \\
\text { No }\end{array}$ & $\begin{array}{l}15(20.29 \%) \\
38(53.52 \%)\end{array}$ & $\begin{array}{c}1(1.41 \%) \\
17(23.94 \%)\end{array}$ & 0.0546 \\
\hline $\begin{array}{l}\text { Lauren classification } \\
\text { Intestinal } \\
\text { Diffuse } \\
\end{array}$ & $\begin{array}{l}28(41.18 \%) \\
22(32.35 \%)\end{array}$ & $\begin{array}{c}6(8.82 \%) \\
12(17.65 \%)\end{array}$ & 0.1684 \\
\hline $\begin{array}{l}\text { Angiolymphatic Invasion } \\
\text { Detected } \\
\text { Not detected }\end{array}$ & $\begin{array}{l}25(37.88 \%) \\
25(37.88 \%)\end{array}$ & $\begin{array}{c}3(4.55 \%) \\
13(19.70 \%)\end{array}$ & 0.0412 \\
\hline $\begin{array}{l}\text { H. pylori infection } \\
\text { Yes } \\
\text { No }\end{array}$ & $7(11.29 \%)$ & $38(61.29 \%)$ & 0.4267 \\
\hline
\end{tabular}

TNM, tumor-node-metastasis

Table 2. Paired comparison of Siglec-15 staining in neoplastic cells, non-transformed and metaplasia adjacent gastric tissue.

\begin{tabular}{lccccc} 
& Non-cancerous & Neoplastic & Metaplasia & \\
Siglec-15 & $(+)$ & 17 & 53 & 9 & $<0.0001$ \\
Siglec-15 & $(-)$ & 40 & 18 & 13 & $<0.0001$ \\
\hline
\end{tabular}


with high TNM (III+IV; 66.04\%) showed Siglec-15 staining in cytoplasm and multiple cellular compartments compared with patients with low TNM stage (I+II; 7.55\%).

Additional analysis, including age, sex, type of surgery, initial treatment, nodal status, radiotherapy, chemotherapy, lymph node, $H$. pylori infection and Lauren classification were not significant. In relation to overall survival, for Siglec-15 positive were 337 days and 501 days for the negative group ( $\mathrm{p}=0.2692)$; to disease-free survival, negative e positive groups had a mean survival of 18 and 14.5 months, respectively $(\mathrm{p}=0.3929)$ and were not statistically significant (Figure 2). Siglec-15 was also confirmed as a predictor of histological grade in GC by multivariate analysis (Table 3), as well as Lauren Classification.

Table 3. Univariate and multivariate Cox regression analysis of histological grade in GC patients.

\begin{tabular}{lcccccccc}
\multirow{2}{*}{ Variable } & \multicolumn{4}{c}{ Univariate } & \multicolumn{4}{c}{ Multivariate } \\
Siglec-15 & OR & $95 \%$ & CI & P & OR & $95 \%$ & CI & P \\
Lauren classification & 0.12 & 0.03 & 0.47 & 0.002 & 0.07 & 0.00 & 0.52 & 0.009 \\
\hline Chirurgical stage & 0.04 & 0.01 & 0.14 & 0.000 & 0.02 & 0.04 & 0.12 & 0.000 \\
\hline
\end{tabular}

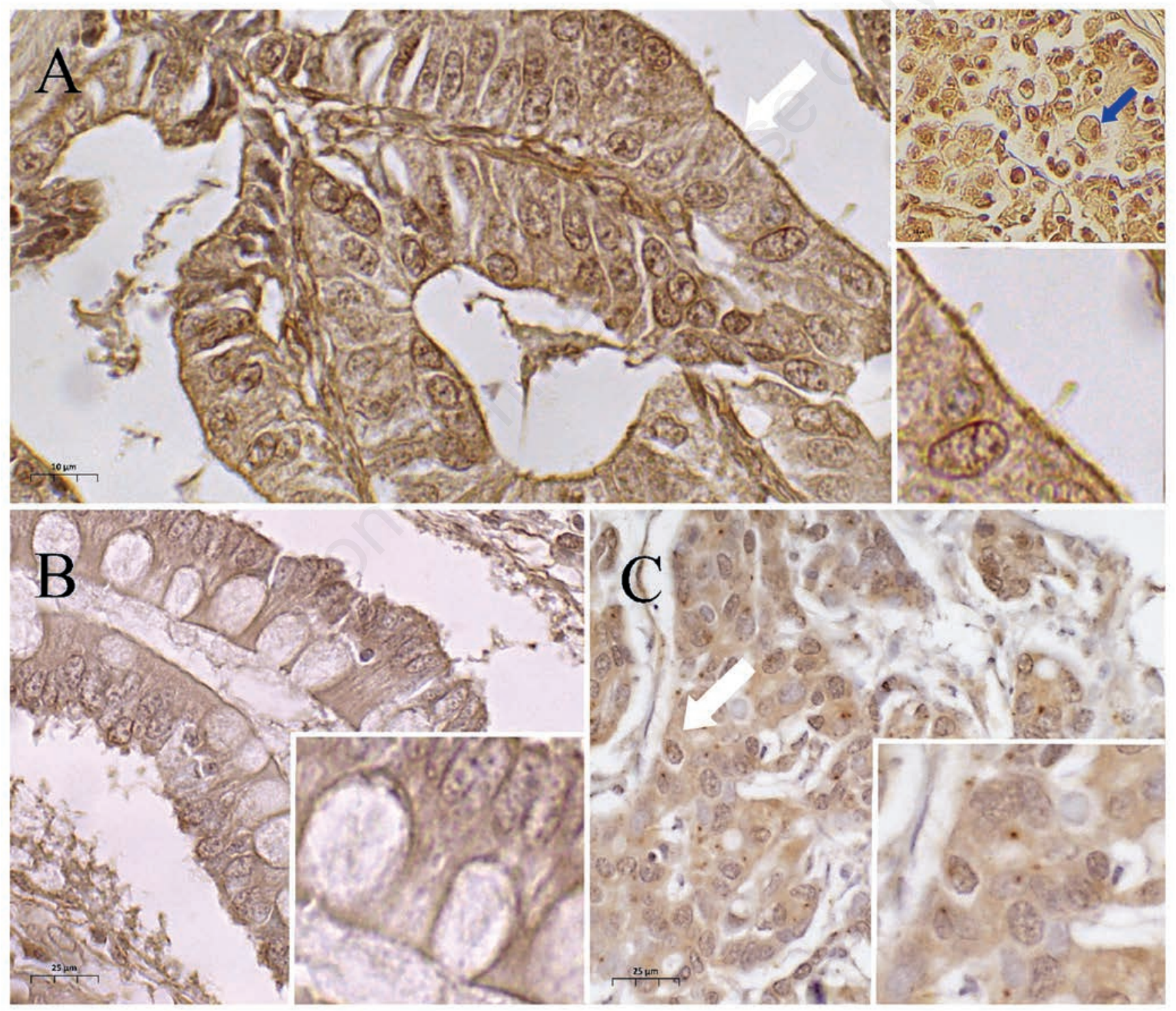

Figure 1. Immunohistochemical labelling for Siglec-15 in GC samples. A) Membrane staining (white arrow) and myeloid cells (blue arrow) in the microenvironment. B) Positive metaplasia. C) Cytoplasmic and nuclear staining (white arrow). 


\section{Discussion}

In the present study, it was demonstrated for the first time that Siglec-15 expression was present in most CG cases. Siglecs have the role of distinguishing the self from the non-self-antigens and glycoprotein sialylation is a process that masks neoplastic cells during carcinogenesis. ${ }^{17}$ The expression of Siglec-15 was significantly higher in the areas of metaplasia and neoplasia compared to areas of normal tissue. In cancer, the production of soluble mucins can negatively regulate the immune response, by binding with Siglecs receptors in Natural Killer cells, dendritic cells and monocytes. ${ }^{18}$ In this way, the high expression of Siglecs reduces the innate immunity response against cancer cells by negatively regulating the immune response to sialylated antigens.

A study based on the TCGA database revealed that Siglec-15 is upregulated in many types of human tumors compared to normal tissues. ${ }^{19}$ However, no significant differences were observed in cholangiocarcinoma, stomach adenocarcinoma, glioblastoma multiforme, and clear cell renal carcinoma. In our study, almost $75 \%$ of the total samples were Siglec-15 positive and $59.70 \%$ presented an adjacent normal tissue. Only considering this adjacent tissue, we found that $42.5 \%$ were Siglec- 15 positive. Taking into account that $\mathrm{Li}$ et al. ${ }^{19}$ have analyzed Siglec-15 mRNA expression from correspondent normal tissues whereas we focus on the characterization of Siglec-15 protein staining in GC tissues and adjacent areas, differences were already expected. This is because, as well as analyzed molecular levels (mRNA and protein), the nature of healthy samples (normal corresponding and adjacent tissue) is also different.

Wang et al. collaborators evaluated Siglec-15 in non-small cell lung cancer samples and found that this protein was present in both neoplastic cells and tumor-associated stromal cells. ${ }^{5}$ In the present study, Siglec-15 was also detected in macrophages, corroborating the potential role of this protein in modulating the immune system. Recent studies have identified Siglec-15 as a potential new target for immunotherapy due to its immune suppressive role in tumor microenvironment. ${ }^{5,20}$ These studies show that Siglec-15 is upregulated in neoplastic cells and overexpressed in macrophages and suppressor cells derived from the myeloid lineage, while few normal myeloid cells express Siglec15. Additionally, Takamiya et al. demonstrated that Siglec-15 is expressed in a subset of tumor-associated macrophages, in a coculture model with THP-1 cells (macrophages-derived) and H157 (human lung carcinoma). ${ }^{21}$

It would be interesting to evaluate the programmed status of ligand-1 death (PDL-1) in these GC samples to investigate whether the expression of Siglec-15 is mutually exclusive to that of PDL-1, as observed in lung adenocarcinoma. ${ }^{5}$ Immunotherapy against cancer using PD-1/PD-L1 blockade has impacted the treatment of several neoplasms. However, these immunological checkpoints are responsible for only a partial dysfunctional immunity in human solid tumors and many patients who respond initially acquire resistance to these therapies with recurrent diseases. ${ }^{22}$ Therefore, researching new immunological normalizers will increase the possibilities of immunotherapy against cancer. A phase I clinical trial is underway to assess the effect of humanized anti-Siglec-15 (NC318) on solid tumors and new findings are highly anticipated.

We demonstrate that the high expression of Siglec-15 was closely related to the most differentiated histological grade, maintained in the multivariate analysis. Siglecs abnormal expression is correlated with disease progression and prognosis in many cancer types, such as hepatocellular carcinoma, acute myelocytic leukemia and lung cancer. ${ }^{23-26}$ In GC, low expression of intratumoral Siglec-8 was a significant negative prognostic factor for patients. ${ }^{27}$ Since in Brazil the GC diagnosis is late and occurs in more advanced stages of disease, characteristic present in the cohort evaluated where $50 \%$ of patients had poorly differentiated GC, the higher expression of Siglec-15 observed in well and moderate differentiated compared to poorly differentiated GC, lead us infer that this expression can act as a good prognostic factor.

The high-affinity binding of Siglecs to mucins and N-glycosylated glycoproteins ${ }^{28}$ has been associated with poor prognosis, ${ }^{29}$ tumor progression inhibition of anti-tumor immune

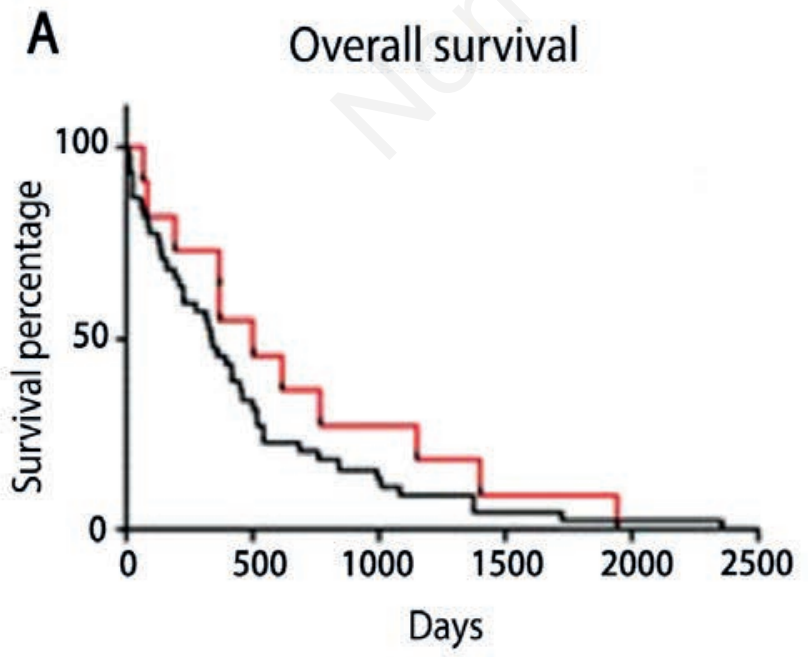

B

Relapse free time

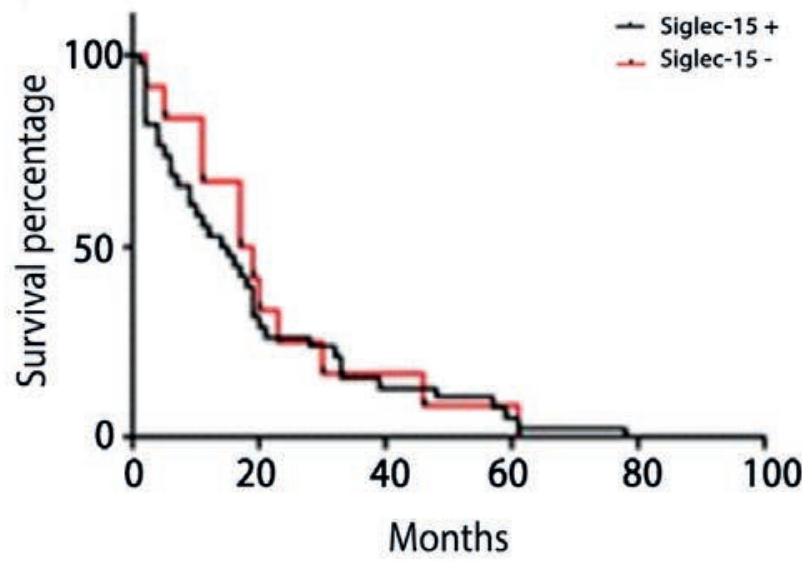

Figure 2. Associations with the outcome parameters. Overall survival Siglec-15 (p=0.2692) (A) and disease-free survival ( $\mathrm{p}=0.6852)(\mathrm{B})$, Overall survival $(p=0.3799)$. 
responses and metastasis. ${ }^{30,31}$ In metastatic models, the Siglecs role in downregulation of NK cell cytotoxicity was associated with favorable circumstances for survival and metastasis while the use of the anti-Siglec antibody was related to prevention of the metastasis development and improved survival. ${ }^{32,33}$ Despite the reports associated with metastasis, to our knowledge this is the first study to relate Siglec's expression to angiolymphatic invasion indicating that further studies should be performed to establish the role of Siglec-15.

To date, there are no studies that have evaluated the expression of Siglec-15 according to the degree of differentiation of tumors. Thus, our data are precursors in demonstrating associations of this lectin with a well and moderately differentiated histological grade, with more advanced staging, and with angiolymphatic invasion. However, bigger investigations are needed to elucidate the role of Siglec-15 in of the tumor microenvironment, as well as in GC progression.

\section{Acknowledgments}

We acknowledge the support by Coordenação de Aperfeiçoamento de Pessoal de Nivel Superior (CAPES) and Conselho Nacional de Desenvolvimento Científico e Tecnológico (CNPq).

\section{References}

1. Luebke T, Baldus SE, Grass G, Bollschweiler E, Thiele J, Dienes HP, et al. Histological grading in gastric cancer by Ming classification: Correlation with histopathological subtypes, metastasis, and prognosis. World J Surg. 2005; 29:1422-7.

2. Bray F, Ferlay J, Soerjomataram I, Siegel RL, Torre LA, Jemal A. Global cancer statistics 2018: GLOBOCAN estimates of incidence and mortality worldwide for 36 cancers in 185 countries. CA Cancer J Clin 2018;68:394-424.

3. Matsuoka T, Yashiro M. Biomarkers of gastric cancer: Current topics and future perspective. World J Gastroenterol 2018;24:2818-32.

4. Ohtsubo K, Marth JD. Glycosylation in cellular mechanisms of health and disease. Cell 2006;126:855-67.

5. Wang J, Sun J, Liu LN, Flies DB, Nie X, Toki M, et al. Siglec-15 as an immune suppressor and potential target for normalization cancer immunotherapy. Nat Med 2019;25:656-66.

6. Peixoto A, Relvas-Santos M, Azevedo R, Lara Santos L, Ferreira JA. Protein glycosylation and tumor microenvironment alterations driving cancer hallmarks. Front Oncol 2019;9:1-24.

7. Mereiter S, Balmaña M, Campos D, Gomes J, Reis CA. Glycosylation in the era of cancer-targeted therapy: Where are we heading? Cancer Cell 2019;36:6-16.

8. Munkley J, Elliott DJ. Hallmarks of glycosylation in cancer. Oncotarget 2016;7:35478-89.

9. Brown Chandler K, E. Costello C, Rahimi N. Glycosylation in the tumor microenvironment: implications for tumor angiogenesis and metastasis. Cells 2019;8:544.

10. Chung CY, Yin B, Wang Q, Chuang KY, Chu JH, Betenbaugh MJ. Assessment of the coordinated role of ST3GAL3, ST3GAL4 and ST3GAL6 on the $\alpha 2,3$ sialylation linkage of mammalian glycoproteins. Biochem Biophys Res Commun 2015;463:211-5.

11. Angata T, Tabuchi Y, Nakamura K, Nakamura M. Siglec-15: An immune system Siglec conserved throughout vertebrate evolution. Glycobiology 2007;17:838-46.

12. Kizuka Y, Nakano M, Yamaguchi Y, Nakajima K, Oka R, Sato K, et al. An alkynyl-fucose halts hepatoma cell migration and invasion by inhibiting GDP-fucose-synthesizing enzyme FX, TSTA3. Cell Chem Biol 2017;24:1467-78.e5.

13. Friedrichs K, Gluba S, Eidtmann H, Jonat W. Overexpression of p53 and prognosis in breast cancer. Cancer 1993;72:3641-7.

14. De Souza Albuquerque MS, Da Silva-Filho AF, Ferraz Cordeiro M, Deodato de Souza MF, Quirino MWL, Amorim Lima LR, et al. GalNAc-T15 in gastric adenocarcinoma: Characterization according to tissue architecture and cellular location. Eur J Histochem 2018;62:2931.

15. Sanchez-Vega F, Mina M, Armenia J, Chatila WK, Luna A, $\mathrm{La} \mathrm{KC}$, et al. Oncogenic signaling pathways in the cancer genome atlas. Cell 2018;173:321-37.e10.

16. Cancer Genome Atlas Research Network. Comprehensive molecular characterization of gastric adenocarcinoma. Nature 2014;513:202-9.

17. Fuster MM, Esko JD. The sweet and sour of cancer: Glycans as novel therapeutic targets. Nat Rev Cancer 2005;5:526-42.

18. Hudak JE, Canham SM, Bertozzi CR. Glycocalyx engineering reveals a siglec-based mechanism for NK cell immunoevasion. Physiol Behav 2014;10:69-79.

19. Li Q-T, Huang Z-Z, Chen Y-B, Yao H-Y, Ke Z-H, He X-X, et al. Integrative analysis of siglec-15 mRNA in human cancers based on data mining. J Cancer 2020;11:2453-64.

20. Ren X. Immunosuppressive checkpoint Siglec-15: a vital new piece of the cancer immunotherapy jigsaw puzzle. Cancer Biol Med 2019;16:205-10.

21. Takamiya R, Ohtsubo K, Takamatsu S, Taniguchi N, Angata $\mathrm{T}$. The interaction between Siglec-15 and tumor-associated sialyl-Tn antigen enhances TGF- $\beta$ secretion from monocytes/macrophages through the DAP12-Syk pathway. Glycobiology 2013;23:178-87.

22. Nowicki TS, Hu-lieskovan S, Ribas A. Mechanisms of resistance to PD-1 and PD-L1 blockade. Cancer J 2018;24:47-53.

23. O'Reilly MK, Paulson JC. Siglecs as targets for therapy in immune cell mediated disease. Trends Pharmacol Sci 2009;30:240-8.

24. Tuscano JM, Kato J, Pearson D, Xiong C, Newell L, Ma Y, et al. CD22 antigen is broadly expressed on lung cancer cells and is a target for antibody-based therapy. Cancer Res 2012;72:5556-65.

25. Wang S, Chen X, Wei A, Yu X, Niang B, Zhang J. a2,6-linked sialic acids on N-glycans modulate the adhesion of hepatocarcinoma cells to lymph nodes. Tumor Biol 2015;36:885-92.

26. Zhang P, Lu X, Tao K, Shi L, Li W, Wang G, et al. Siglec-10 is associated with survival and natural killer cell dysfunction in hepatocellular carcinoma. J Surg Res 2015;194:107-13.

27. Cao Y, Liu H, Zhang H, Lin C, Li R et al. Decreased expression of Siglec-8 associates with poor prognosis in patients with gastric cancer after surgical resection. Tumor Biol 2016;37:10883-91

28. Läubli H, Alisson-Silva F, Stanczak MA, Siddiqui SS, Deng L, Verhagen A et al. Lectin galactoside-binding soluble 3 binding protein (LGALS3BP) is a tumor-associated immunomodulatory ligand for CD33-related Siglecs. J Biol Chem 2014;289:33481-91.

29. Gendler SJ. MUC1, the renaissance molecule. J Mammary Gland Biol Neoplasia 2001;6:339-53.

30. Belisle JA, Horibata S, Jennifer GAA, Petrie S, Kapur A, 
André S et al. Identification of Siglec-9 as the receptor for MUC16 on human NK cells, B cells, and monocytes. Mol Cancer 2010;9:118.

31. Beatson R, Tajadura-Ortega V, Achkova D, Picco G, Tsourouktsoglou TD, Klausing S et al. The mucin MUC1 modulates the tumor immunological microenvironment through engagement of the lectin Siglec-9. Nat Immunol 2016;17:1273-81.

32. Kawasaki Y, Ito A, Withers DA, Taima T, Kakoi N, Saito S, et al. Ganglioside DSGb5, preferred ligand for Siglec-7, inhibits NK cell cytotoxicity against renal cell carcinoma cells. Glycobiology 2010;20:1373-9.

33. Tuscano JM, Kato J, Pearson D, Xiong C, Newell L, Ma Y et al. CD22 antigen is broadly expressed on lung cancer cells and is a target for antibody-based therapy. Cancer Res 2012;72:5556-5.

Received for publication: 23 August 2020. Accepted for publication: 9 February 2021.

This work is licensed under a Creative Commons Attribution-NonCommercial 4.0 International License (CC BY-NC 4.0).

(C) Copyright: the Author(s), 2021

Licensee PAGEPress, Italy

European Journal of Histochemistry 2021; 65:3174

doi:10.4081/ejh.2021.3174 